\title{
EDITORIAL
}

\section{SEM at 75: foreword}

\author{
Antonio Ventosa ${ }^{1} \cdot$ Rafael Giraldo ${ }^{2}$
}

Published online: 18 November 2021

(c) The Author(s), under exclusive licence to Springer Nature Switzerland AG 2021

Seventy-five years is indeed a unique occasion to have a long-sighted view to the past of a Scientific Society, such as the Spanish Society for Microbiology (SEM). SEM was founded in 1946, shortly after the turmoil of the Spanish Civil War, when so many things, outdoors and indoors of Academia, needed healing and reconstruction and the microbiologists did their best to bring back the country to an internationally relevant position in the sphere of our discipline. However, such vision would be rather short-sighted if we will not make use of a really successful past as a springboard for projection towards the future.

International Microbiology, the official journal of SEM, was born in 1947 as "Microbiología Española" and mutated into "Microbiología SEM" in 1986, then christened in 1998 with its current name to be now published by Springer Nature since 2018. With this special issue, the 1,700 members of our Society, female and male researchers, either veterans or young, working in universities and other academic or research institutions and in companies across Spain and abroad, we all celebrate this milestone event.

In a first block or articles ("The ongoing scientific venture"), a selection of representative laboratories ("they are all who are but they are not all who are") present, most of them as reviews, their frontline research on a broad spectrum of topics in Microbiology. Francis Mojica and co-workers review the CRISPR-Cas universe from the perspective of the implications of its astonishing diversity for the biology of microorganisms. Fernando Baquero gives a fresh (and hopeful) perspective on the global menace of antibiotic resistance. On their side, Víctor de Lorenzo and colleagues

Antonio Ventosa

ventosa@us.es

Rafael Giraldo

rgiraldo@cnb.csic.es

1 Department of Microbiology and Parasitology, Faculty of Pharmacy, University of Sevilla, Sevilla, Spain

2 Department of Microbial Biotechnology, National Centre for Biotechnology (CSIC), Madrid, Spain propose a novel conceptual framework for approaching microbial systems with concepts imported from Economic Theory. Íñigo Lasa reviews the emergent evidence on a role for the non-phosphorylated form of response regulators in bacterial two components systems. María Molina, Humberto Martín and their colleagues discuss their contributions unveiling the central role of the Slt2 MAP kinase in the cascade that controls yeast cell wall integrity. Alicia Prieto, María J. Martínez and co-workers review the potential of the glycosyl hydrolases from the fungus Talaromyces amestolkiae for plant biomass biotechnology, with a focus in their enzymology and engineering. Continuing with eukaryotic microorganisms, Francisco Amaro and Ana Martín discuss the impact of protists, through bacterial predation, in the evolution and virulence of antibiotic resistance by shaping the bacterial genomes and training bacteria for future encounters with macrophages. Fungi have a central role in biodeterioration of sites such as caves with parietal art, a subject explored by Cesáreo Saíz-Jiménez and his colleagues from the perspective of the airborne transmission of these microorganisms depending on the local climatic conditions. Lorena Ruíz, Abelardo Margolles and their team review the most advanced methods used at the food industry to assess microbial biosafety, with a focus on Next Generation DNA sequencing. Jesús Romalde and his colleagues adopted a similar approach for the taxonomic analysis of the microbiota in the tissues of two clam species, a subject that impacts on aquaculture. Alex Mira, Saray Aranda-Romo and colleagues report their finding that Streptococcus dentisani is globally spread in the oral microbiome of cariesfree individuals, which has broad implications for human dental health. Finally, Gemma Reguera and her co-workers deepen in the genetics of the amazing electroactive biofilms assembled by Geobacter sulfurreducens, exploring the effect of genome-wide transposon gene disruption in their development.

In the second part of this issue ("Roots, context and outreach"), César Nombela provides his personal reflections and perspectives on the history of SEM, with a focus on the European scenario. On their side, Juan Ayala and Roberto 
Kolter expose their views on the transatlantic relations between Spanish and Latin-American microbiologists, with an account of their personal experiences. Closing this special issue, Manuel Sánchez-Angulo, Ignacio L. Goñi and Víctor J. Cid discuss, from their perspectives as Microbiology teachers at distinct universities in Spain, the challenge that the COVID-19 pandemic has imposed on the academic community, accounting for the responses (virtual learning and the "Micromundo" initiative, among others) that kept the torch of Microbiology lit at the campuses.

We hope that our fellow microbiologists colleagues will enjoy with the contents of this issue, thus joining us in this very special celebration. And for SEM, we wish a happy 75th birthday and a scientifically worth and sound life for the future, with our eyes already fixed on the Centenary!

Publisher's note Springer Nature remains neutral with regard to jurisdictional claims in published maps and institutional affiliations. 